\title{
POLYCYSTIC OVARIAN SYNDROME;
}

\section{ACNE IS COMMON PRESENTATION IN WOMEN IN RELATION TO MENSTRUAL IRREGULARITY A STUDY FROM HOSPITAL IN KARACHI.}

\section{Dr. Shazia Shukar-ud-Din, Dr. Sadaf Ahmed Asim, Dr. Syeda Rabia, Dr. Rumina Tabassum, Dr. Aisha Razzaque.}

ABSTRACT.....Background: Polycystic ovarian syndrome is a common disease among the women in reproductive age group and more common in South Asian women. Clinical presentations include menstrual disorders, subfertility, obesity,hirsutism, acne vulgaris and acanthosis. Objectives: The objective of study was to investigate co relation between acne and polycystic ovaries and its relation to menstrual irregularity. Methodology: A total of 56women were enrolled in the study from Outpatient Department of Obs\&Gynae and Dermatology, Dow University Hosptial, Ojha campus by convenient sampling. It was cross sectional study, conducted from July 2012 to November 2012.Verbal consent was taken. Sociodemographic information,Anthropometric measurement (height, weight, BMI) and acne severity with affected area, menstrual irregularities were administered on pre designed questionnaire.Pelvic ultrasound for polycystic ovaries and serum LH, FSH in follicular phase of menstrual cycle (2nd day) advised from Dow Radiology and Dow Lab respectively. Results: A total of56 patients of PCOS were enrolled during five month period. The mean age of patient was $21.1+$ SD 0.994. Frequency of acne was 32 (57.1\%). The mean BMI was $19.66+$ SD 4.54. Face was the commonest area involved in 24 (42.9\%). menstrual irregularity was found in 50 (89.4\%) women. There was no statistically significant relation seen between acne and oligomenorrhea. $(X 2=0.55, P=0.45)$. It was also determined that there was no co relation seen between the acne and serum testosterone level calculated by independent sample t test. $(P=0.17)$ but statistically significant association seen between severity of acne and serum LH/FSH ratio. (ttest $=3.28, p=0.004$ ) Conclusion: Acne was found in $32(57.1 \%)$ women with PCOS. The study results revealed a significant association seen between severity of acne and serum LH/FSH ratio. Relation between acne and serum testosterone level was statistically insignificant.

Key words: Polycystic ovary syndrome, Acne, Menstrual irregularity.

Article Citation

Shukar-ud-Din S, Asim SA, Rabia S, Tabassum R, Razzaque A. Polycystic ovarian syndrome; acne is common presentation in women in relation to menstrual irregularity a study from hospital in karachi. Professional Med $\mathrm{J}$ 2013;20(5): 719-725.

\section{INTRODUCTION}

Polycystic ovarian syndrome is one of the most common hormonal disorders affecting the women. It has the major effect on metabolic, endocrine, reproductive health throughout the life ${ }^{1}$. It affects 5$10 \%$ of all women ${ }^{2}$. PCO is diagnosed in $21 \%-33 \%$ women on the basis of ultrasonography ${ }^{3}$. In 2003, the European Society for Human Reproduction and Embryology and American Society for Reproduction introduced the Rotterdam criteria. It is the presence of two out of three criteria. 1) Oligo-and/or anovulation. 2) Clinical and/ or biochemical signs of hyperandrogenism. 3) Polycystic ovaries syndrome assessed by ultrasound ${ }^{4}$. ESHRE / ASRM consensus group, define polycystic ovaries as containing 12 or more follicles measuring 2-9mm and / or increased ovarian volume of $>10 \mathrm{~cm}^{5}$.

It is a multigenic complex disorder, including the abnormality of hypothalamic pituitary ovarian axis, steroidogenesis and insulin resistance ${ }^{6}$. The usual sign and symptoms with PCOS areoligo or amenorrhea, infertility, hirsutism, acne, polycystic ovaries, insulin resistance, androgen excess and elevated $\mathrm{LH} / \mathrm{FSH}$ ratio. Dermatological features include acne vulgaris, acanthosis nigricans, hirsutism and androgenetic alopecia but in severe cases signs of virilization?

Hyperandrogenism manifested with varying severity and it affects sebaceous glands (hirsuitism, acne, alopecia) and ovulatory functions (oligomenorrhea, infertility) ${ }^{8}$.

Prevalence of acne has been reported in 10-34\% women of PCOS in different studies ${ }^{9}$. Acne vulgaris is disease of pilosebecous unit characterized by the formation of papule, pustules, nodules and cyst. 
Sebum production increased in women with acne due to increased androgen which cause the retention of keratinocytes around the sebaceous hair follicle. So there is partial or complete blockage, bacterial colonization and infection. There is high prevalence of acne in women with PCOS proved by different studies.Acne is common manifestation of hyperandrogenemia. In the female the most common cause of hyperandrogenemia is polycystic ovary syndrome. Studies also have shown that high concentration of testosterone occur in $60-80 \%$ women with $\mathrm{PCOS}^{10-11-12}$.

The objective of study was to investigate co relation between acne and polycystic ovaries and its relation to menstrual irregularity. As there is wide range of presenting symptoms of PCOS, the aim of study is to emphasize the need to consider investigations of PCOS in women with acne and menstrual irregularities.

\section{PATIENTS \& METHODS}

The present study is the cross sectional study carried out in Outpatient Department of Obstetrics \& Gynaecology and Dermatology Department of Dow University Hospital. The study was carried out from July 2012 to November 2012.

Total 56 patients were enrolled in the study by convenient sampling. The women who presented with acne and associated menstrual irregularity in Gynaecology \& Dermatological OPD and each patient met the Rotterdam criteria for the diagnosis of polycystic ovary syndrome were included in the study. Women who were pregnant, taken medication for treatment of acne, other endocrinological disorder excluded from the study. Prior to data collection nature of research was explained to participants and consent was taken. A predesigned questionnaire was filled. Data was collected on sociodemoraphic information, Anthropometric measurement (height, weight, BMI) and acne severity with affected area, menstrual irregularities, also noted. Every patient advised for pelvic ultrasonography (during early follicular phase) to rule out polycystic ovaries, sent to Dow Radiology Department. Hormonal profile advised from Dow Laboratory in follicular phase (2nd day of cycle), which include (serum LH, FSH, LH/FSH ratio, serum insulin, serum testosterone and SHBG). The normal ranges of hormonal level were, (Serum FSH: follicular phase 1.4-9.9 $\mathrm{mlU} / \mathrm{ml}$, Serum LH: follicular phase 1.7-15.0mIU /ml, SerumTestosterone: Adult female $0.52-2.43 \mathrm{nmol} / \mathrm{l}$.

Statistical analysis was performed by using SPSS recent version. Chi-square analysis was performed to test for differences in proportions of categorical variables between the two groups. Student t test (two tailed) was used to determine the significance of difference between two continuous variables.

\section{RESULTS}

Total 56 patients were enrolled in the study. Sociedemographic characteristics of the patients are outlined in Table-I. The mean age of patient was21.1+_SD 0.994.It was found that $17(30.4 \%)$ were between 15-20 years,22(39.3\%) were between 21-25 years, 12 (21.4\%) were of them between 26-30 years and $5(9 \%)$ of them were $31-35$ years or older. 35 (62.5\%) patients were single and $21(37.5 \%)$ were married. Majority of women $32(62.5 \%)$ belonged to upper middle class. The mean BMI was $19.66+$ SD4.54. It was determined that $14(25 \%)$ of the patients had normal BMI, $28(50.0 \%)$ were overweight, $9(16.1 \%)$ were obese and $5(9 \%)$ of them were found underweight. It was found that $12(21.4 \%)$ patients had no children, $7(12.5 \%)$ had one child and $3(5.4 \%)$ had two or more than two children. On the other hand $35(62.5 \%)$ of them were unmarried.In this study majority of patients $48(85.7 \%)$ belonged to Urdu speaking language and remaining were from other ethnicities. It was determined that $17(30.35 \%)$ women aged 15-20, 22(39.28 \%) women aged between 21 and 25years, 12 (21.42\%) women aged 
between 26 and 30 years and 4 (7.1\%) women aged between 31 and 35 years found different acne severity. In this study no positive relation was found between acne severity and age. $(X 2=14.11$, $P=0.29$ ). It was determined that acne severity not related positively with $\mathrm{BMI}$ ( $\mathrm{t}$ test $=1.958, \mathrm{P}=0.06$ ) $50(89.4 \%)$ women had menstrual irregularity, out of which $38(67.9 \%)$ women presented with oligomenorrhea.

\begin{tabular}{|c|c|c|}
\hline & Frequency & \%age \\
\hline $\begin{array}{l}\text { Age distribution (years) } \\
\qquad \begin{aligned} 15-20 \\
21-25 \\
26-30 \\
31-35 \\
36-40\end{aligned}\end{array}$ & $\begin{array}{c}17 \\
22 \\
12 \\
4 \\
1\end{array}$ & $\begin{array}{c}30.9 \\
38.2 \\
21.8 \\
7.3 \\
1.8\end{array}$ \\
\hline $\begin{array}{l}\text { Marital status } \\
\text { Married } \\
\text { Single }\end{array}$ & $\begin{array}{l}21 \\
35\end{array}$ & $\begin{array}{l}37.5 \\
62.5\end{array}$ \\
\hline $\begin{array}{c}\text { Parity distribution } \\
0 \\
1 \\
2 \text { and more } \\
\text { Unmarried }\end{array}$ & $\begin{array}{c}12 \\
7 \\
3 \\
34\end{array}$ & $\begin{array}{c}21.4 \\
12.5 \\
5.4 \\
60.7\end{array}$ \\
\hline $\begin{array}{c}\text { Ethnicity } \\
\text { Urdu speaking } \\
\text { Non Urdu speaking }\end{array}$ & $\begin{array}{l}48 \\
08\end{array}$ & $\begin{array}{l}85.7 \\
14.3\end{array}$ \\
\hline $\begin{array}{c}\text { Socioeconomic status } \\
\text { Lower } \\
\text { Lower middle } \\
\text { Upper middle } \\
\text { Upper }\end{array}$ & $\begin{array}{c}6 \\
14 \\
35 \\
01\end{array}$ & $\begin{array}{c}10.7 \\
25 \\
62.5 \\
1.8\end{array}$ \\
\hline $\begin{array}{l}\text { Level of education } \\
\text { Illiterate } \\
\text { Primary } \\
\text { Secondary } \\
\text { Intermediate } \\
\text { Graduates } \\
\text { Postgraduates }\end{array}$ & $\begin{array}{c}2 \\
2 \\
6 \\
26 \\
16 \\
4\end{array}$ & $\begin{array}{c}3.6 \\
3.6 \\
10.7 \\
46.4 \\
28.6 \\
7.1\end{array}$ \\
\hline
\end{tabular}

Table-I. Sociedemographic characteristics $(\mathrm{N}=56)$

Acne were found in 32(57.1\%) women with PCOS, out of which $9(16.1 \%)$ had mild acne, 11(19.6\%) had moderate and $12(21.4 \%)$ had severe acne. If we discuss about the location of acne, we determined that the face was the commonest area involved and it was
$24(42.9 \%)$. Face, thorax and back was involved in $3(5.4 \%)$ of patients. but we did not found a significant co relation of oligomenorrhea with acne severity. $(X 2=1.09, P=0.77)$. It was also determined that there was no statistically significant relation seen between acne and oligomenorrhea. $(X 2=0.55, P=0.45)$.

\begin{tabular}{|c|c|c|c|}
\hline $\begin{array}{c}\text { Anthropometric } \\
\text { measurement }\end{array}$ & Mean+_SD & Minimum & Maximum \\
\hline Height (m2) & $1.61+\_0.042$ & 1.52 & 1.76 \\
\hline Weight (kg) & $63.26+\_1.331$ & 41.0 & 103.0 \\
\hline BMI (Kg/m2) & $19.66+\_4.54$ & 13.00 & 31.30 \\
\hline LH/FSH ratio & $1.625+\_0.787$ & $1: 1$ & $5: 1$ \\
\hline Serum LH (mlU/ml) & $9.59+\ldots 6.83$ & 1.58 & 47.90 \\
\hline Serum FSH (mlU/ml) & $7.06+\_4.19$ & 3.20 & 34.00 \\
\hline $\begin{array}{l}\text { Serum Testosterone } \\
(\mathrm{nmol} / \mathrm{l})\end{array}$ & $1.44+\_1.21$ & 0.13 & 4.50 \\
\hline
\end{tabular}

Table-II. Anthropometric measurement and hormonal profile $(\mathrm{N}=56)$

\begin{tabular}{|c|c|c|}
\hline Acne \& acne severity & Chi square & p-value \\
\hline Acne severity and age & 14.11 & 0.29 \\
\hline Acne severity and oligomenorrhea & 1.09 & 0.77 \\
\hline Acne and oligomenorrhea & 0.55 & 0.45 \\
\hline Acne and polycystic ovaries on ultrasound & 0.536 & 0.91 \\
\hline
\end{tabular}

Table-III. Relation of different variables with acne and severity of acne.

\begin{tabular}{|c|c|c|}
\hline Acne \& acne severity and hormonal levels & $\begin{array}{l}\text { T test (Independent } \\
\text { sample) }\end{array}$ & p-value \\
\hline Acne and level of serum LH & 0.29 & 0.76 \\
\hline Acne and level of serum FSH & 0.29 & 0.12 \\
\hline Acne and level of serum testosterone & 0.40 & 0.17 \\
\hline Acne severity and serum LH/FSH ratio & 3.28 & $\mathbf{0 . 0 0 4}$ \\
\hline Table-IV. Relation of hormonal levels with acne and severity of acne.
\end{tabular}

It was also found that $39(69.6 \%)$ patients showed picture of PCO on ultrasound while remaining $17(30.4 \%)$ had normal ultrasound of pelvis. It was determined that $17(30.35 \%)$ women found PCOS on pelvic ultrasonography out of which $7(12.5 \%)$ had no acne, so there was no statistically significant relation found between acne and polycystic ovaries. $(X 2=0.536, P=0.911)$.

Independent sample T test was applied for the mean 
significant difference between acne and serum testosterone level, serum LH, FSH level, and serum LH and $\mathrm{FSH}$ ratio. There was no statistically significant difference seen between acne and level of serum $\mathrm{LH}$ and FSH. (t test; 0.29), $(p=0.76, \quad p=0.12)$ respectively. It was also determined that there was no statistically significant seen between the acne and serum testosterone level calculated by independent sample t test. $(P=0.17)$ When we determined relation between acne and level of serum LH \& serum FSH, we found them statistically insignificant (t test $=0.29$, $P=0.76, \quad(P=0.12) \quad$ respectively. Statistically insignificant difference was found between acne and serum $\mathrm{LH} / \mathrm{FSH}$ ratio. $(\mathrm{P}=0.39)$ but statistically significant difference seen between severity of acne and serum LH/FSH ratio. (t test $=3.28, p=0.004$ )

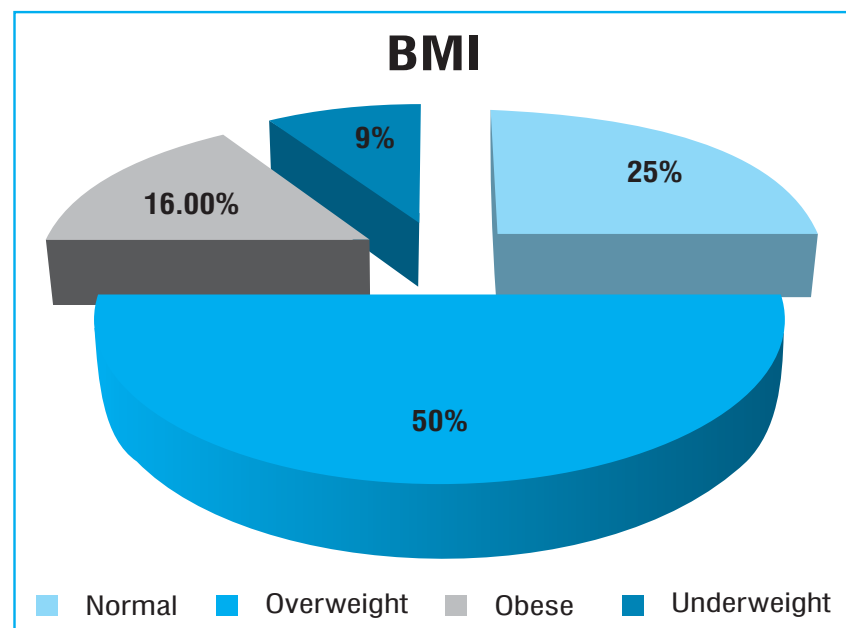

Fig.1

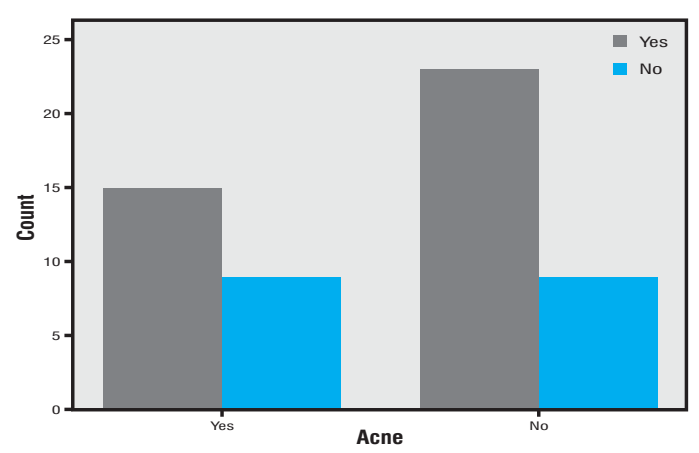

Fig.2: Relation between acne and oligomenorrhea

\section{DISCUSSION}

In our study acne were found in $32(57.1 \%)$ women with PCOS, out of which 9 (16.1\%) had mild acne, $11(19.6 \%)$ had moderate and 12(21.4\%) had severe acne. Study conducted by Borgia et al found that prevalence of PCO was $19 \%$ in women with acne ${ }^{14}$.

One study conducted by Salepour et al in Tehran on adolescent. That study found acne in $31.3 \%$ of participants ${ }^{15}$.

Studies show that prevalence of acne varies with ethnicity as shown by different studies. It is reported higher in Asian Indians ${ }^{16}$ and lower in Pacific islanders ${ }^{17}$.

Study conducted by Falsetti $L$ et al in Italy acne was present in $23.4 \%$ PCOS women ${ }^{18}$.

Another study found that $14.5 \%$ of patients of PCOS presented with acne ${ }^{19}$. In study conducted by Archer and colleagues many women with PCOS found acne and in $50 \%$ of women lesion seen in neck, chest and upper back ${ }^{20}$. A study conducted in India by Sharma D et al. They found acne in $73.68 \%$ of PCOS women and $24 \%$ had oligomenorrhea ${ }^{21}$.

In this study there was no relation found between age and acne. These results were not consistent with study conducted byGouldenet al, who foundthat acne was reported in almost all teenagers and more than half of the women greater than age of $25^{22}$.

Our study found no association between acne severity and polycystic ovaries on pelvic ultrasonography,this is again not consistent with study conducted by Lurassich and colleague. They reported $c 0$ - relation of acne with polycystic ovaries and found that subsequent phases of acne correlated with clinical severity of polycystic ovary. The study population in this study was $19-28$ years $^{23}$. 
In our study, no positive correlation seen between acne and level of serum testosterone level.

Various studies have been coated in literature, shown positive and negative relation between acne severity and hyperandrogenism. Study conducted on adult women by Cibula and colleagues reported no positive correlation between the acne severity and clinical and biochemical markers of hyperandrogenism. In these women polycystic ovaries found in $50 \%$ of women ${ }^{24}$.

Study conducted in Italy in adult women to evaluate co relation between severity of acne and endocrinological parameters, there was no statistically significant association found between acne severity and BMI. This result is consistent with our study ${ }^{18}$. These results are consistent with our study.

Study conducted by Azziz et al found that 60 to $80 \%$ women with PCOS had elevated circulating androgen levels ${ }^{13}$, they found elevation in free testosterone level in majority of patients. This is not consistent with our study.

The prevalence of acne was $53 \%$ in study conducted by Ozdemir et al. This study was conducted to assess the various dermatological features. In this study acne was not associated with hormonal, metabolic and anthropometric variables and $50 \%$ women with acne did not have the clinical or biochemical evidence of hyperandrogenism ${ }^{25}$.

Another study conducted by Bunker et al found that there was no correlation between acne severity and polycystic ovaries, menstrual disturbances and endocrinological abnormalities. They studied 98 women who presented with acne vulgaris ${ }^{26}$.

In study conducted in Thailand reported that $37.3 \%$ women of PCOS presented with acne out of which $39.2 \%$ had abnormal menstruation. In the same study acne cases had higher level of androgen,that was not consistent with our study ${ }^{27}$.

The finding of our study supported by another study conducted by Ewadh MJ et al. In this study serum LH \& FSH showed no significant changes between patient and control group. Only LH/FSH ratio was increased ${ }^{28}$.

\section{CONCLUSION}

The present study revealed that acne was found in 32 $(57.1 \%)$ women with PCOS. The study results concluded that significant association seen between acne severity and serum LH/FSH ratio\&statistically insignificant association found between acne severity and serum testosterone level\& menstrual irregularity in women with PCOS.

\section{RECOMMENDATION}

Some form of acne occurs in all teenager girls and women, so it should be keep in mind that it could be a clinical feature of PCOS. All women presented with acne should also ask for their menstrual cycle pattern and advised for hormonal profile and pelvic ultrasound to rule out polycystic ovaries.

\section{Copyright $\odot 12$ Mar, 2013.}

\section{REFERENCES}

1. David A, EhrmannMD. Polycystic ovarian syndrome. N Eng J Med. 2005; 352:1223-36.

2. Wang HS, Wang TH. Polycystic ovarian syndrome, insulin resistance and insulin like growth factors (IGFs) / IGF-Binding proteins. Chang Gung Med J, 2003; 26:540-52.

3. Shohayeb A, Shaltout A, Farouk A et al. Ultrasonically diagnosed polycystic ovaries in asymptomatic women with normal hormonal profile does not affect their fecundity. MEFSJ. 2005;10:116-224.

4. Balen A. Polycystic ovary syndrome and secondary amenorrhea. In: Edmonds. D. K, ed. Dewhurst's Textbook of Obstetrics and Gynaecology. 8th ed. Massachusetts: Blackwell publishing; 2012: 513-33. 
5. Rotterdam ESHRE / ASRM- Sponsored PCOS Consensus Workshop Group. Revised 2003 consensus on diagnostic criteria and long term health risks related to polycystic ovary syndrome. FertilSteril. 2004; 81:19-25.

6. Yarak S, Bagatin E, Hassun KM et al. Hyperandrognism and skin: polycystic ovary syndrome and peripheral insulin resistance. An Bras Dermatol. 2005; 80:16.

7. Lee AT, Zane LT. Dermatologic menefestations of polycystic ovary syndrome. Am J ClinDermatol. 2007; 8: 201-19.

8. Chanukvadze D, Kristesashvili J, Kvashilava N. Co relation of biochemical markers and clinical signs of hyperandrogenism in women with polycystic ovary syndrome and women with non classic congenital adrenal hyperplasia. Iran J Reprod Med. 2012; 10:307-14.

9. Chuan SS, Chang RJ. Polycystic ovary syndrome and acne. Skin therapy letter. 2010; 15:1-8.

10. Buccola JM, Reynolds EE. Polycystic ovary syndrome. A review for primary providers. Prime care. 2003; 30:697-710.

11. Dekkers OM, Thio BH, Romijn JA, Smit JW. Acne vulgaris endocrine aspect. Ned Tijdschr Geneesked. 2006;150: 220-30.

12. Whitney KM, Ditre CM. Management strateigies for acne vulgaris. ClinCosmetlnvestig Dermatol.2011;4: 41-53.

13. Azziz R, Carmina E, Dewailly D, Diamanti - Kandarakis E et al. Position statement: criteria for defining polycystic ovary syndrome as a predominantly hyperandrogenic syndrome: An androgen excess society guideline. J Clin EndocrinolMetab. 2006; 91:4237-45

14. Borgia F, Cannavo S, Guarneri F, Cannavo SP, Vaccaro $M$, Guarneri B. Correlation between endocrinological parameters and acne severity in adult women. ActaDerm Venereol.2004; 84:201-4.
15. SalepourS, Shirwani HE, Entezari A. Evaluation of prevalence of polycystic ovarian syndrome among the adolecsents (15-18 years old) girls in Tehran during 2005-2006. IJFS. 2010; 4(3):122-27.

16. Wijeyaratne CN, Balen AH, Barth JH, Belchetz PE. Clinical manifestation and insulin resistance in polycystic ovary syndrome among South Asians and Cucascians. Is there a difference? ClinEndocrinol. 2002; 57:343-50.

17. Williamson K, Gunn AJ, Jhonson N, Milsom SR. The impact of ethnicity on the presentation of polycystic ovarian syndrome. Aust N Z J Obstet Gynecol. 2001; 41:202-6.

18. Falsetti L, Gambera A, Andrico S, Sartori E. Acne and hirsutism in polycystic ovary syndrome: clinical, endocrine-ultrasonographic differences. Gynecol Endocrinol 2002; 16:275-84.

19. Azziz R, Sanchez LA, Knochenhauer ES, Moran C et al. Androgen excess in women: experience with over 1000 consecutive patients. J ClinEndocrinolMetab. 2004; 89:453-62.

20. Archer JS, Chang RJ. Hirsutism and acne in polycystic ovary syndrome. Best PractRes ClinObstetGynaecol. 2004;18: 737-54.

21. Sharma D, Shanker V, Tegta G, Gupta M, Verma GK Clino- investigative profile of patients of hirsutism in a tertiary level institution. Int J Trichol. 2012; 4:69-74.

22. GouldenV, Stables GI, Cunliffe WJ. Prevalence of facial acne in adults. J Am AcadDermatol. 1999; 41(4): 577 80.

23. lurassich S, Trotta C, Palagiano A, Pace L. Correlation between acne and polycystic ovary. A study of $\mathbf{6 0}$ cases. Minerva Ginecol. 2001; 53:107-11.

24. Cibula D, Hill M, Vohradnikova 0, Kuzel D et al. The role of androgen in determining the acne severity in adult women. Br J Dermatol. 2000; 143:399-404.

25. Ozdemir S, Ozdemir M, Gorkemli H, Kiyici A, Bodur S. Specific dermatologic features of the polycystic 
ovary syndrome and its association with biochemical markers of the metabolic syndrome and hyperandrogenism. ActaObstetGynecol Scand. 2010; 89:199-204.

26. Bunker CB, Newton JA, Kilborn J, Patel A et al. Most women with acne has polycystic ovaries. $\mathrm{Br} J$ Dermatol. 1998; 121:675-80.
27. Timpatanpong P, Rojanasajul A. Hormonal profiles and prevalence of polycystic ovary syndrome in women with acne. J Dermatol. 1997; 24(4): 223-9.

28. Ewadh MJ, Shemran KA et al. The correlation of some hormone with acne vulgaris. I.J.S.N. 2011; 2:713-17.

\section{AUTHOR(S):}

1. DR. SHAZIA SHUKAR-UD-DIN

Assistant Professor of Obstetrics \& Gynaecology

Dow International Medical College,

Dow University Hospital Ojha Campus, Karachi.

2. DR. SADAF AHMED ASIM

Assistant Professor Dermatology

Dow International Medical College,

Dow University Hospital Ojha Campus, Karachi.

3. DR. SYEDA RABIA

Associate Professor Obstetrics \& Gynaecology

Dow International Medical College,

Dow University Hospital Ojha Campus, Karachi.

4. Dr. Rumina Tabassum

Associate Professor Obstetrics \& Gynaecology

Dow International Medical College,

Dow University Hospital Ojha Campus, Karachi.
5. Dr. Aisha Razzaque

Senior Registrar Obstetrics \& Gynaecology

Sind Government Hospital, Saud abad.

Correspondence Address:

Dr. Shazia Shukar-ud-Din

Assistant Professor of Obstetrics \& Gynaecology

Dow International Medical College,

Dow University Hospital Ojha Campus, Karachi. drshazia2010@hotmail.com

\section{PREVIOUS RELATED STUDIES}

Shahid Irshad Rao, Rashida Sadiq, Hina Kokab. POLYCYSTIC OVARIAN DISEASE; THE DIAGNOSIS AND MANAGEMENT (Original) Prof Med Jour 13(2) 186-191 Apr, May, Jun, 2006.

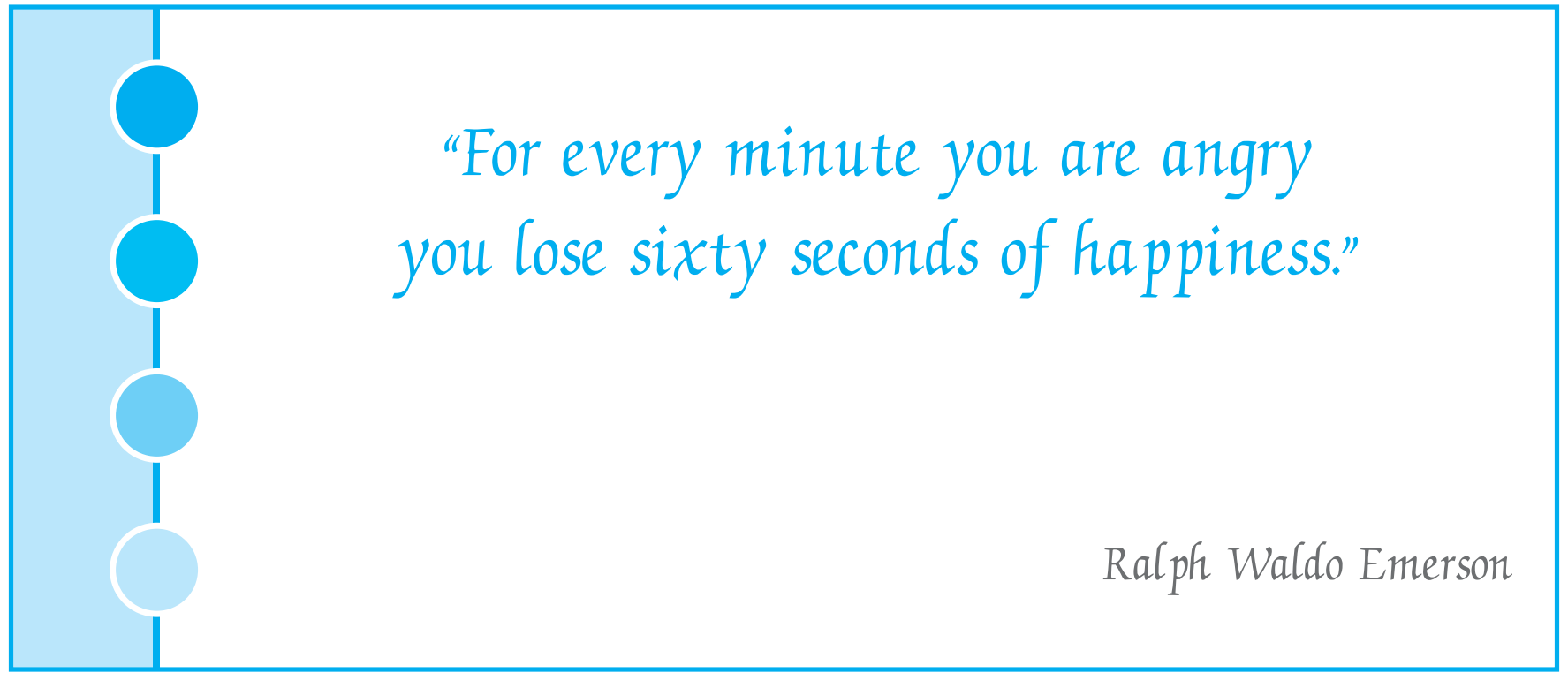

